\title{
Probe into the Application of PBL Teaching Method and Practice Reform in the Teaching of Medicinal Botany
}

\author{
Yanjiao Li, Zhilu Zhang, Guang Qi, Huashan Gao* \\ Pingdingshan University Pingdingshan City, Henan Province, 467000, \\ Exploration of Mixed Teaching Mode of Pharmacy Based on OBE Concept.2020-WSKJ-0934
}

\begin{abstract}
Medicinal botany is a discipline that studies traditional or folk knowledge about the use of plants to prevent and treat diseases, and it is an important part of Chinese medicine learning. Traditional teaching methods do not perform well in the teaching of medicinal plants. Therefore, in order to improve the teaching effect of medicinal botany, teachers need to continuously research and innovate teaching methods to improve the quality of teaching. This article is guided by the PBL teaching method, and studies the application of the PBL teaching method in the teaching of medicinal plants in detail, hoping to improve the learning effect of students and improve the teaching quality of medicinal botany.
\end{abstract}

Keywords: PBL Teaching Method; Practice Reform; Medicinal Botany; Teaching Application

As the global environment continues to deteriorate, a variety of new diseases emerge in an endless stream, and with the abuse of antibiotics, many bacteria are becoming more and more resistant. Based on this, scientists will hope to put them into traditional plant medicine and hope that through research The medicinal ingredients in natural plants solve the current serious disease prevention and control problems. Therefore, more and more people pay attention to medicinal botany. Medicinal botany has the advantages of innate environment in our country, but because the theoretical knowledge of the subject has a certain degree of abstraction, the content that needs to be memorized is too complicated, and students are required to have strong practical and hands-on skills. Because of the difficulty, many students "cannot learn the method". For this reason, the author combined many years of medicinal botany teaching experience and analyzed in detail the application effect of PBL teaching method in medicinal botany teaching practice, aiming to improve students better The learning efficiency of medicinal botany.

\section{Main concepts and characteristics of PBL teaching method}

PBL is the abbreviation for the initials of Problem-Based Learning in English, and is also known as problembased teaching. It is a teaching method that is oriented to teaching problems and adheres to a student-centered teaching method. It is very different from the traditional subject-based teaching method. It has received a very good response in teaching practice. The development trend of teaching.

The PBL teaching method has the following main characteristics: First of all, the PBL teaching method is based on the problem as the starting point for learning. All teaching activities are developed around the problem and have very distinct target characteristics. Secondly, the design of the problem must be a real problem that the students may meet in the future study or work. To ensure the rationality and authenticity of the problem, the difficulty of the problem should be moderate. Finally, students should be the teaching center, and students should be organized to carry out independent, cooperative, and inquiry-based learning, and self-evaluation and group evaluation should be carried out after completing the problem, so as to consolidate the learning effect and improve the effectiveness of course teaching.

Copyright (C) 2020 Yanjiao Li et al.

doi: 10.18282/le.v9i7.1501

This is an open-access article distributed under the terms of the Creative Commons Attribution Non-Commercial License

(http://creativecommons.org/licenses/by-nc/4.0/), which permits unrestricted non-commercial use, distribution, and reproduction in any medium, provided the original work is properly cited. 


\section{Design ideas and application process of PBL teaching method in the teaching of medicinal botany}

Combining the teaching goals of botany and the society's requirements for relevant talents, students not only need solid theoretical knowledge, but also need to have strong practical application skills. Therefore, when teachers use the PBL teaching method to teach medicinal plants, they should design the teaching process according to the cultivation of students' abilities, help students develop good learning habits, and improve their own comprehensive qualities.

\subsection{Clarify teaching objectives and raise curriculum questions}

Before actual teaching, teachers need to let students clarify the teaching goals of the course through multimedia equipment or in the form of micro-classes, and combine the content of the course to ask students questions related to the teaching theme, and guide students to focus on the problem. Thinking about it. For example, in real life, ginseng has many names in different regions, and the medicinal mechanism of the plant used to use the word "ginseng" is different. Teachers should guide students to find and summarize these plants, which is convenient for students. To avoid memory confusion, on the one hand, students can have a deeper understanding of this type of medicinal plants and enhance their interest in active learning.

\subsection{Teaching in groups, analyzing teaching problems}

After completing the teaching problem setting, the teacher needs to group the students reasonably according to the specific situation of the students, and let the students discuss the problems raised in groups. In the process of group analysis and discussion, teachers need to clarify the respective tasks and responsibilities of students within the group, maximize the spirit of unity and cooperation, and maximize the efficiency of students' learning. In addition, teachers need to give students time to analyze problems, encourage students to search for relevant materials through the Internet or the library in their spare time, and gather and organize the efforts of all students to get answers to questions.

\subsection{Solve the problem through hard work}

In the process of solving problems for students, teachers should interfere with students' thinking and judgment as little as possible, observe the students' problem-solving progress as much as possible, and appropriately guide and guide them so that students can solve problems through their own efforts. Let students gain a sense of accomplishment and pride in the process of solving problems, and enhance students' enthusiasm for continuing learning. This method is an important form of expression with students as the main body of teaching. Teachers should re-adapt themselves to their role as guides in teaching, change the focus of teaching from knowledge teaching to method teaching, cultivate students to form scientific research ideas, and improve students to solve problems Ability..

\subsection{Evaluation of learning effect after task completion}

Evaluating the results obtained by students after the problem is completed is the last and most important part of the PBL teaching method. Teachers need to evaluate the conclusions drawn by different groups, not only to judge the results of the problem, but also to evaluate the specific analysis process and problem-solving ideas. Only by effectively combining the process and results can students truly understand Own deficiencies and advantages, in order to improve the comprehensive ability of students. In addition, teaching evaluation includes not only the teacher's evaluation of students, but also the students' self-evaluation and the evaluation among students. Only when the three are integrated can the students' learning conditions be reflected most objectively. Therefore, both teachers and students should pay attention to the final evaluation to ensure the effectiveness of PBL teaching.

\section{Concluding remarks}

The PBL teaching method attaches importance to the establishment of teaching problems, helps students clarify their learning goals at the first time, allows students to control their learning progress autonomously, gives full play to their dominant position in teaching, and makes their learning more efficient and free. Therefore, in order to improve the effectiveness of medicinal botany, teachers can appropriately use PBL teaching method according to the teaching content, fully mobilize students' enthusiasm for learning, enhance and give play to their subjective initiative, exercise and culti- 
vate students' self-learning and inquiry spirit, and be effective Improve students' learning efficiency and improve their comprehensive qualities.

\section{References}

1. Wang Di, Wang Lin. The application and thinking of PBL combined with field practice teaching method in medicinal botany teaching[J]. Education Teaching Forum, 2020, No.464(18):260-262.

2. Wang Zhanyi, Wang Hongkai, Zhang Lihua, et al. The application of "five in one" teaching method in the course of medicinal botany_taking labiatae plants as an example[J]. Journal of Guangxi University of Traditional Chinese Medicine, 2018, 21(03):112-115.

3. Chen Xiuhua. Application practice of flipped classroom teaching model based on micro-class in medicinal botany[J]. Education Teaching Forum, 2020, No.465(19):241-242. 